\title{
Learning Management System in Education: Opportunities and Challenges
}

\author{
Thouraya Snoussi
}

\begin{abstract}
Traditional teaching and learning methods have undergone a reform shift with the integration of ICT tools, especially learning management systems (LMS). They are emphasized as essential tools in the educational system. This paper examines the use LMS in higher education in the UAE. Based on semi-structured interviews conducted in the winter of 2018 and summer of 2019, the study revealed that 54 participants unanimously identified the highest degree of need for active participation in the investment of modern technologies within their universities. They mentioned a number of opportunities offered by the use of the Learning Management System (LMS) in the emirate educational institutions such as: The ease of organizing and delivering online courses, conducting online assessments, access to and availability of learning materials, the possibility of saving time and money for students and faculties, communication and interactivity. Respondents seem to be aware of some challenges in adopting the Learning Management System in their respective universities, particularly the lack of self-discipline of students in the online environment, the inconsistency of the Learning Management System with some academic programs offered in a number of emirate higher educational institutions, limited use of Arabic language and technical illiteracy.
\end{abstract}

\section{Keywords: ICT- LMS- E-Learning - Education}

\section{INTRODUCTION}

$T_{\text {he advantages of learning management systems are not }}$ yet very clear in many universities of the Arab world. For this reason, it is essential that academics in Arab universities play a pivotal role in instilling technological innovation by supporting integrated programs and adopting them as a modern means of teaching and learning.

In this research, the author chose to explore a number of views and trends first, regarding the nature of technological uses in faculties' sample workplaces in the UAE, especially LMS ; and then, regarding the most important challenges they face while trying to invest technology systems effectively in the learning process within their universities.

\section{LITTERATURE REVIEW}

There have been various researches on the uses of ICTs in education. Thus, the researcher chose to address only studies related to the use of technologies in the UAE because they are directly related to the current research topic.

Revised Manuscript Received on October 31, 2019.

*Thouraya Snoussi*, Associate Professor, Mass Communication Department, College of Communication, University Of Sharjah, UAE. Email: tsnoussi@sharjah.ac.ae
Kamel Ben Salama [1] in his study entitled "ICT in Education in the UAE: An investigation into the use of ICT poster workshops on 'Road Safety Campaigns' with Male Emirati Students", Emphasized the need to integrate ICT into the tertiary education. He used a mixed methods approach. Results showed that the participants' use of ICT to produce "Road Safety" posters was motivating and engaging. Besides, ICT was able to unveil the participants' perceptions towards driving behavior and attitudes. The study encountered a number of limitations mainly the unavailability of data from the UAE Ministry of Education on the systematic and strategic plans for the inclusion of ICT in teaching and learning in the UAE.

Carmen Millen [2], through his investigative research article entitled 'IPad IPedagogy: A study of teacher' perceptions on the impact of the IPad on teaching and assessment practices at a third level college in the United Arab Emirates", explored teachers' perceptions of the opportunities and challenges associated with the adoption of the iPad. The findings report both opportunities and limitations associated with the device and identify a core list of applications. The paper concluded with recommendations to help alleviate factors which teachers identified as challenges and discusses approaches which could be adopted by policy makers and administrators which could help teachers maximize the potential of the iPad to help launch a new era of innovative, learner-centered education.

Mouakket and Bettayeb [3], in their study "Factors Affecting University Instructors Continuance Intention to Use Learning Management Systems: The Blackboard System Case", tried to investigate the factors affecting instructors' continuance usage intention of the LMS in academic institutions in the United Arab Emirates (UAE). Their findings stipulate that the influence of the Blackboard system design was perceived useful. Authors suggested regular trainings and technical support for users to help them being more at ease of use of the LMS.

Al- Rassoul Ashraf Shawky [4] published a research article entitled "The Knowledge Functionality in the Teachers' Online Social Networks (TOSN) in UAE", where he examined the professional knowledge in the teachers' online social networks (TOSN) in terms of editing and exchanging. The study found that teachers accept these TOSNs because they provide them with professional development and achieve this goal better than traditional programs for professional development. The study has also found that this knowledge is applicable, which positively affects the outcomes of the educational process. 


\section{Learning Management System in Education: Opportunities and Challenges}

The majority of the papers mentioned were based on quantitative methods of information collection. While exploring the uses of LMS in a sample of UAE universities, the current research is supported by a qualitative study. The aim is to deepen the knowledge about the opportunities and challenges of using ICT in higher education in the UAE.

The researcher completed the first part of the current study where she raised the question of the ICT usage in Education. A number of semi structured face-to-face interviews were conducted in Jan.- Mar. 2018, with a sample of academicians selected from four private universities in the UAE, to identify the experience of using new technologies in their learning experience. The result showed that the sample was facing challenges of transformation of curriculum and learning process, mainly in some programs related to colleges of humanities and social sciences.

The author's findings were very significant. She then decided to expand her research on the uses of ICT in the UAE and produce a series of scientific articles focusing each time on one specific technology being used, in order to reach more accurate results and get closer to the reality. The current study focuses on the use of the learning management systems LMS in private universities in Dubai.

\section{METHODOLOGY}

A qualitative approach was employed using semi-structured interviews applied to a sample of faculties working in various private universities in Dubai.

The researcher achieved the first part of the applied study in 2018. 34 semi-structured (face-to-face) interviews were conducted with deans, HOD and programs directors of four (4) private higher education institutions implemented cross UAE: Abu Dhabi, Dubai, Sharjah and Ajman.

The selection of the components of the sample was guided by the author's determination to enrich the research community and make it reflect as much as possible the real situation of all private universities in the UAE. Interviews were conducted between 01/01/2018 and 15/03/2018.

This study represents the second part of the research. It was conducted during the summer semester of 2019 (Mai - June). It relies on electronic interviews to overcome the distance between the researcher and the participants; part of them was on vacation during the summer and left the country (UAE). 20 semi-structured electronic interviews were conducted. Participants from various private universities in Dubai were contacted by Messenger and invited to participate in a short 15-20 minute discussion on the uses of LMS in their learning experiences.

A sample of five (5) faculties was selected from the following universities located in Dubai: Al Falah University (AFU), the British University in Dubai (BUID), the Canadian University in Dubai (CUD) and the American University in the Emirates (AUE).

As per the first part of the research, the author designed an interview guide using the TEDS Approach (tell, explain, describe, suggest). The interviews data was ready for analysis through qualitative data analysis (QDA) computer software "Hyper Research" which was partially used. When the data was incompatible with the software, a manual procedure was used.

\section{RESULT AND DISCUSSION}

The researcher divided the applied part into two (2) sections based on the data obtained during the interviews:

- Learning Management System uses' opportunities

- Learning Management System uses' challenges

\section{A. Learning Management System uses' Opportunities}

The Data showed that the respondents use two specific learning management systems: Blackboard and Moodle. The choice is guided by financial concerns: Moodle is an open source platform; free for use. Blackboard is commercial/ paid. A consensus was noted regarding specific opportunities offered by LMS from faculties' perspective:

Easy way to organize and present educational content:

According to respondents, LMS help them gather and store educational material in one place, making it available anytime, from any connected device. One respondent from $\mathrm{Al}$ Falah University said: "I have always been careful to store all my handouts, assignments, exams soft copies and all my teaching materials on several hard disks and devices. I thought that is a good solution in case one device is lost or damaged, I can find a spare copy; which is sometimes confusing. But thanks to the LMS I can put everything in one arranged place, easy to use and can be consulted from any computer or smart phone".

A participant from BUID pointed out the benefits of LMS in the arrangement and design of the teaching materials: " $L M S$ helps me design and implement lessons, exams, assignments, and virtual discussions in a modern way to keep up with technological advances. It attracts students' attention more than the traditional boring methods".

Open access:

Respondents presented LMS as an easy tool to access course material. According to them, the LMS characteristics make it accessible and available to all parties within the university's educational system. A faculty from CUD explained:" All students enrolled in the lesson can access the information they need once the faculty has uploaded the materials. This can be done without having to come to the university. The student has to log in into the e-learning platform via his smartphone or his tablet and everything is set! This is one of the main reasons why LMS is necessary in educational institutions, especially in higher education".

Another participant insisted on the LMS flexibility and quickness of use." If you want to update the content from one semester to another or in parallel with the update of the learning outcomes of the lesson, you can simply access the education management system and make the necessary adjustments without re-escalating the entire material".

One participant displayed details of his experience about integrating social network sites such as Facebook and You tube in his course to support the use of LMS as an open source of information. He confirmed that these sites are useful for learners if invested in a creative and smart way to suit the nature of the lessons. 
The same statement was revealed during the first part of the research. Some respondents belonging to the first sample (including 34 participants from four universities in the UAE) defended the value of social media uses in a number of specialized communication and public relations courses. They consider LMS and social media have an integrated role in education. One completes the second.

Easy way for assessment:

Data indicated a consensus on the beneficial role of the learning management system as an assessment tool. Respondents insisted on its ability to track student progress in their assignments and ensure that they are doing what they have been asked for in the classroom. One participant explained: "I can easily assess my students' performance and inform students who are late in assignments' submission before the deadline". Another respondent added: "Thanks to Safe-Assign, i am now able to determine the cheating rates and details in all assignments uploaded on the Blackboard. This makes the assessment process both accurate and simple".

LMS is perceived as an excellent tool for faculties to save a lot of time in grading the assignments and quizzes especially for a large number of students (big size foundation classes).

Money and time saver:

Participants consider the Learning Management System a valuable technological addition in the educational environment. It provides students with the required online material so they can download and view it in a shorter time than buying books and reading pamphlets. One respondent explained: "In some cases, weather conditions prevent students from attending lectures. In other cases, I feel the need to schedule extra courses especially before the final exams period. In such circumstances, online course is the best solution. It saves cost and time for students and me (travel expenses and time consuming)".

Communication and interactivity:

All respondents emphasized on LMS as a communication medium facilitating interactivity and collaboration between faculties and students. According to them, ICT have opened the door wide for constant and regular communication by using announcements, emails, .group discussions...etc.

\section{B. Learning Management System uses' challenges}

Disadvantages of using LMS from respondents' perspective are:

\section{Lack of students' self-discipline}

LMS as a container for e-learning processes often fails because of the freedom space for students in the digital space. Students may not take online courses seriously. A respondent noticed that: "Even during the exams completion, many students usually make random choices without seriously thinking about the questions".

Besides, many students find it easier to understand lessons in a real educational environment (in a classroom), with classmates rather than through an impersonal e-learning module. Face to face communication and interactivity between instructors and students seems to be more popular in the UAE, and ensure greater commitment from students.

Thus, respondents confirm that not all students are totally committed to the online courses experience. They may be distracted or unmotivated. This leads to the lack of self-discipline.

Lack of instructors' input

Respondents admitted their apprehension about LMS uses. They fear that they will not be able to design lessons creatively, or suiting materials in a pre-designed software.

One participant elucidated: "The lesson is designed based on the characteristics of the LMS used in the university. However, learning materials can quickly become outdated and their content can change according to the CLO's updates of each course, which drag instructors to constantly update lessons available online. This process is tiring especially with the steady developments of the technologies themselves".

Other comments take the same direction: "The available management systems themselves are constantly changing, which requires continuous training for faculties' members, so that they can keep up with the technological updates. They are often asked to redesign their online courses and re-post their teaching and learning material. Ifeel like it is a waste of time". Another added: "Instead of taking time to improve the existing online content, we have to focus more on how we redesign it and deliver it to students".

Disproportion with certain academic programs

E-learning should be said to be perfect in implementing a large number of online courses and transferring educational knowledge. However, respondents pointed out that effective learning has to be based on the refinement of students' skills, mainly in practical courses such as Radio and Television presentation and Public speaking. A participant teaching in the Public relations program at $\mathrm{Al}$ Falah University explains: "Media and PR courses require a face-to-face contact with students and intensive practical exercises and repetitions". Another respondent teaching in mass communication program in the AUE elucidated: "Unfortunately, education through LMS is not very useful for some courses and doesn't fit with certain specializations, especially those related to mass communication, humanities and social sciences".

In other words, the assessments that are designed and conducted online generally have a tendency of being only knowledge-based and not necessarily practicality-based. Thus they are more suitable for engineering and science programs than humanities.

Limited usage of the Arabic language

Some respondents belonging to colleges of humanities and social sciences claimed that the limited adoption of the Arabic language in the ICT' environment represents an obstacle to integrate LMS. This made some of them wonder about the feasibility and benefits of use, especially with regard to writing and editing exercises in Arabic. One of the respondents asserted that he is unable to adapt the exercises and exams that rely on editing, with the peculiarities of modern technologies. Same observation was stated by the first sample from faculties affiliated in the college of Arts and humanities in the University Of Sharjah.

Technical literacy

Respondents pointed out that although students are technologically savvy in general, some of them are enable to use some software related to LMS, and therefore cannot follow the faculty' instructions and honor their duties on Blackboard or Moodle. 


\section{Learning Management System in Education: Opportunities and Challenges}

All participants claimed that their respective universities offer series of training courses for new students at the beginning of each semester, but rapid technological developments make all parties confused at times. Some participants noted that a limited number of their colleagues of certain age do not have the technical expertise to use LMS. Older people are simply ignorant of the computer 'uses and continue to give their courses in old ways: writing lessons on the board and reading passages of textbooks in front of students inside the classroom. This category of faculties even refuses to join training courses related to the modern technology uses in education.

In fact, technological competence is essential for both students and faculties to appropriately use LMS and pursuing online courses as it enables them to manage or follow their courses in an effective and unimpeded manner. For these reasons; participants claimed intensive training sessions to maintain a good level of LMS literacy, mainly sessions related to the Blended Learning, course design and assessment tools.

\section{CONCLUSION}

$\mathrm{T}_{\mathrm{H}}$ he study, based on semi-structured interviews conducted in the winter 2018 and summer 2019, revealed a consensus on the importance of LMS insertion in the educational institutions in the UAE.

All participants claimed to be involved in the use of LMS in delivering courses; many of them were enthusiastic enough to make calls with colleagues to deepen their knowledge of new technologies and incorporate LMS into their teaching experience, especially colleagues of a certain age who lacked computer literacy. With regard to the level of uses of LMS, respondents noted that they are in-depth in some disciplines such as science, engineering and medical studies, and marginalized in specialties related to Arts and humanities.

The opportunities offered by the use of LMS in education in the UAE are summarized by the participants as follows: Ease of organizing and delivering online courses and conducting online assessments, accessibility and availability of learning materials, the possibility of saving time and money for students and faculties, communication and interactivity. Respondents cited many challenges they face in adopting these technologies in their respective emirate universities, such as the lack of students' self-discipline, the LMS disproportion with certain academic programs, the limited usage of the Arabic language and the technical literacy.

The results of the current study are consistent with previous studies, mainly on the challenges of LMS.

Salehi [6] confirmed that insufficient technical supports at schools were considered as the major barriers preventing teachers to integrate ICT. The interviewee unanimously claimed their desire for multiple trainings to get familiar with the E-learning environment and to assure its usage.

Al Ismail [7] also linked some of the challenges facing LMS to the difficulty of mastering technology, which may limit the feasibility of adopting it within the educational institution.

Al Samarraie [8] perceived in his last research published in 2018 that prior technology experience of freshmen students may not be sufficient to use the LMS effectively. Students may still find it challenging to organize and manage different ideas in a way that enables them to link and share their individual tacit knowledge.
In the end, it is obvious that most of the challenges to rooting technology in education are related to technical aspects and users' computer literacy. For these reasons, participants in the current research suggested intensifying training courses on the use of LMS for faculties and students as well as the adoption of learning management systems that recognize the Arabic language.

\section{REFERENCES}

1. K. Ben Salama, "ICT in Education in the UAE: An investigation into the use of ICT poster workshops on 'Road Safety Campaigns' with Male Emirati Students", Dissertations for Information and Communication Technology (ICT), Issue 5, 2010. [Online]. Available: https://bspace.buid.ac.ae/handle/1234/161

2. C. Mullen, "iPad iPedagogy: A study of teacher perceptions on the impact of the iPad on teaching and assessment practices at a third level college in the United Arab Emirates", Dissertations for Information and Communication Technology (ICT), Issue 4, 2014. [Online]. Available: https://bspace.buid.ac.ae/handle/1234/477

3. S. Mouakket, and A. Bettayeb. "Factors Affecting University Instructors' Continuance Intention to Use Learning Management Systems: The Blackboard System Case". In Proceedings of the 18th International Conference on Enterprise Information Systems (ICEIS 2016) - Volume 2, pages 215-222- ISBN: 978-989-758-187-8

4. A. Al Rassoul. "The Knowledge Functionality in the Teachers' Online Social Networks (TOSN) in the UAE". Dissertations for Information and Communication Technology (ICT), Issue3, 2019. [Online] Available: https://bspace.buid.ac.ae/handle/1234/477

5. T. Snoussi "ICT faculties' usage in the UAE private universities: A case study, Global Media Journal, Volume 17, Issue 33, Sep. 2019- ISSN 1550-7521. [Online]. Available :http://www.globalmediajournal.com/ArchiveGMJ/articleinpress-globa 1-media-journal.php

6. O. A. Al-Ismaiel, "Collaborative blended learning with higher education students in an Arabic context", Doctor of Philosophy thesis, Faculty of Education, University of Wollongong, 2013. [Online]. Available: https://ro.uow.edu.au/theses/3983

7. O. A. Al-Ismaiel, Op. Cit.

8. H. Al Samarai \& N. Said, "A systematic review of cloud computing tools for collaborative learning: Opportunities and challenges to the blended-learning environment", computers \& education journal, Vol 124, Sep. 2018, pp. 77-91. [Online]. Available: https://doi.org/10.1016/i.compedu.2018.05.016

\section{AUTHORS PROFILE}

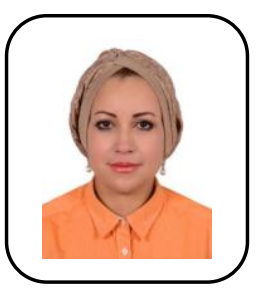

Dr.Thouraya Snoussi, Associate Professor in Communication and Media, Academic Coordinator College of Communication, University Of Sharjah (UAE).

Dr. Thouraya received her $\mathrm{PhD}$. from Stendhal University- France, started her professional caree as Radio and TV Journalist in Tunisia and Canada, where she gained a rich professional experience in Journalism and communication. She moved to teaching field in 2006 as assistant professor at Manouba University, then at Emirates College of Technology in Abu Dhabi. She then moved to the College of Mass Communication in Al Ghurair University, where she served as Associate Professor, Head of Department and then Acting Dean of the College.

Her area of research includes new technologies of information and communication and their effects on Media and Education; she published 5 books and more than 35 refereed research articles in English, French and Arabic. She got international recognitions: "Leader in Humanities and Social Sciences" in Jan. 2018, in Chennai, "Woman in Education Leadership Award", in July2018, in Singapore and "Best Faculty Award" in Jun. 2019, in Noida. 